\title{
Compartimentação geomorfológica e processos deposicionais no megaleque fluvial do rio São Lourenço, Pantanal mato-grossense
}

\author{
Fabrício Anibal Corradini ${ }^{1,2 *}$, Mario Luis Assine ${ }^{2}$
}

\begin{abstract}
Resumo A planície sedimentar do Pantanal é um extenso trato deposicional moderno, no qual megaleques fluviais são as feições que mais se destacam, sendo o do rio Taquari o maior e mais conhecido. Também notável é o megaleque do rio São Lourenço, que, apesar de possuir área de cerca de $16.000 \mathrm{~km}^{2}$, é ainda pouco conhecido nos seus aspectos geológicos e geomorfológicos. Situado na borda noroeste do Pantanal, o megaleque do São Lourenço coalesce com o do Taquari, sendo dele separado pela planície fluvial interleque do rio Piquiri. Com base na interpretação de dados orbitais e na sua validação em campo, foi possível identificar padrões de canais, interpretar processos sedimentares, reconhecer fenômenos de avulsão fluvial e delinear lobos deposicionais. Foram reconhecidos três compartimentos geomorfológicos no megaleque do São Lourenço: 1) lobos deposicionais abandonados indiferenciados, situados na porção proximal/média do megaleque e constituídos por sedimentos pleistocênicos depositados por paleocanais distributários, atualmente em dissecação por canais tributários; 2) cinturão de meandros de idade holocênica, limitado por terraços marginais e resultado de agradação fluvial em vale inciso, cuja direção está condicionada por estruturas N65E; 3) lobos deposicionais ativos, situados na porção distal do megaleque e principal área de sedimentação do sistema deposicional, caracterizados por frequentes eventos de avulsão, bifurcações do canal, padrão de drenagem distributária e presença de lóbulos deposicionais. Os lobos deposicionais ativos foram formados a partir de importante evento de avulsão fluvial, que culminou com o abandono da porção inferior do cinturão de meandros.
\end{abstract}

Palavras-chave: Pantanal; rio São Lourenço; megaleque fluvial; compartimentação geomorfológica; processos deposicionais.

\begin{abstract}
Geomorphological zonation and depositional processes on the São Lourenço fluvial megafan, Pantanal wetland, Brazil. The Pantanal wetland is an extensive depositional tract characterized by the presence of fluvial megafans, from which that of the Taquari River is the most extensive and well known. Located on the northern border of the Pantanal, the São Lourenço megafan is a large distributary fluvial system with an area of $16,000 \mathrm{~km}^{2}$, but poorly known regarding its geomorphological and geological features. The Sao Lourenço and the Taquari are coalescent megafans, having the Piquiri interfan meander river in between them. Based on the interpretation of satellite images and field validation, it was possible to identify channel patterns, to interpret depositional and erosional processes, to recognize the phenomena of river avulsion and to map depositional lobes. Three geomorphological zones were recognized on the São Lourenço megafan: 1) abandoned depositional lobes located in the upper/intermediate fan, composed of Pleistocene fluvial deposits and exhibiting distributary paleochannels on their surfaces, which are currently being dissected by tributary channels; 2) an active Holocene confined meander belt formed by fluvial aggradation in a N65E incised-valley; 3) active depositional lobes placed on the distal part of the system, which are the main site of sedimentation and are characterized by frequent avulsion events, channel bifurcation, distributary drainage pattern and the presence of depositional lobated landforms. The active depositional lobes were formed due to an important event of river avulsion that caused the lower portion of the meander belt to be abandoned.
\end{abstract}

Keywords: Pantanal wetland; São Lourenço River; fluvial megafan; geomorphological zonation; depositional processes.

\author{
INTRODUÇÃO \\ O Pantanal mato-grossense \\ é uma extensa planície aluvial alojada na Depressão \\ do Alto Paraguai, com área de aproximadamente \\ $138.000 \mathrm{~km}^{2}$ e cotas altimétricas inferiores a \\ 200 m. O rio Paraguai é o rio tronco do sistema \\ hidrográfico, coletando as águas de todos os rios \\ que drenam os planaltos circunvizinhos e chegam \\ à planície do Pantanal.
}

A maioria dos rios oriundos dos planaltos adquire padrão de drenagem distributário ao adentrar na planície do Pantanal, formando sistemas deposicionais de leques fluviais (Assine 2003; Assine \& Soares 2004). Vários deles apresentam grandes dimensões, sendo denominados megaleques. $\mathrm{O}$ megaleque do Taquari, com cerca de $50.000 \mathrm{~km}^{2}$, é o maior e o mais estudado deles (Assine 2005, Assine et al. 2005).

${ }^{1}$ Faculdade de Geografia, Universidade Federal do Pará - UFPA, Marabá (PA), Brasil. E-mail: f_coradini@yahoo.com.br ${ }^{2}$ Programa de Pós-graduação em Geociências e Meio Ambiente, Departamento de Geologia Aplicada, Universidade Estadual Paulista "Júlio de Mesquita Filho" - UNESP, Rio Claro (SP), Brasil. E-mail: assine@rc.unesp.br

*Autor correspondente 
Embora seja um dos menos conhecidos em termos geológicos e geomorfológicos, o megaleque do rio São Lourenço impressiona pelas suas dimensões e pelas evidências de mudanças ambientais frequentes, tanto pretéritas quanto atuais. $\mathrm{O}$ megaleque do São Lourenço está situado a norte do megaleque do Taquari, sendo o contato entre ambos definido pela planície fluvial do rio Piquiri (Fig. 1). O megaleque se desenvolve no flanco norte da bacia sedimentar do Pantanal, cuja espessura de sedimentos ultrapassa os $200 \mathrm{~m}$ na parte distal do leque (Assine 2004).

A bacia de drenagem do rio São Lourenço, situada a leste nos planaltos dos Guimarães e do Taquari-Itiquira, tem área de aproximadamente $24.000 \mathrm{~km}^{2} \mathrm{e}$ altitudes que decrescem de cerca de $800 \mathrm{~m}$ nos divisores de água para cerca de 200 m na saída para o Pantanal. A bacia encontra-se alojada num grande anfiteatro de erosão, facilmente visualizado em modelos digitais de elevação (Fig. 2).

O amplo anfiteatro de erosão foi esculpido sobre rochas paleozóicas dos grupos Rio Ivaí (Formações
Alto Garças e Vila Maria), Paraná (Formações Furnas e Ponta Grossa) e Itararé (Formação Aquidauna). A dissecação é desigual e os vales mais profundos, situados na saída para o Pantanal, cortam rochas cristalinas pré-cambrianas do Grupo Cuiabá, que na área constituem o embasamento da bacia sedimentar do Paraná. A densidade de drenagem é baixa, resultado da natureza dos arenitos paleozóicos, que se apresentam muito fraturados e com boa permoporosidade. A dissecação do relevo encontra-se em estágio juvenil a maduro e os rios apresentam vales íngremes e leito dominantemente rochoso, por isso os canais apresentam baixa mobilidade e margens estáveis. A rede de drenagem está condicionada por fraturas e falhas que controlam o traçado dos canais, caracterizados por apresentarem segmentos retilíneos de poucos quilômetros, orientados predominantemente nas direções N40E, N65E e N50W.

A maior parte da bacia de drenagem é drenada pelo rio Vermelho, principal afluente do São

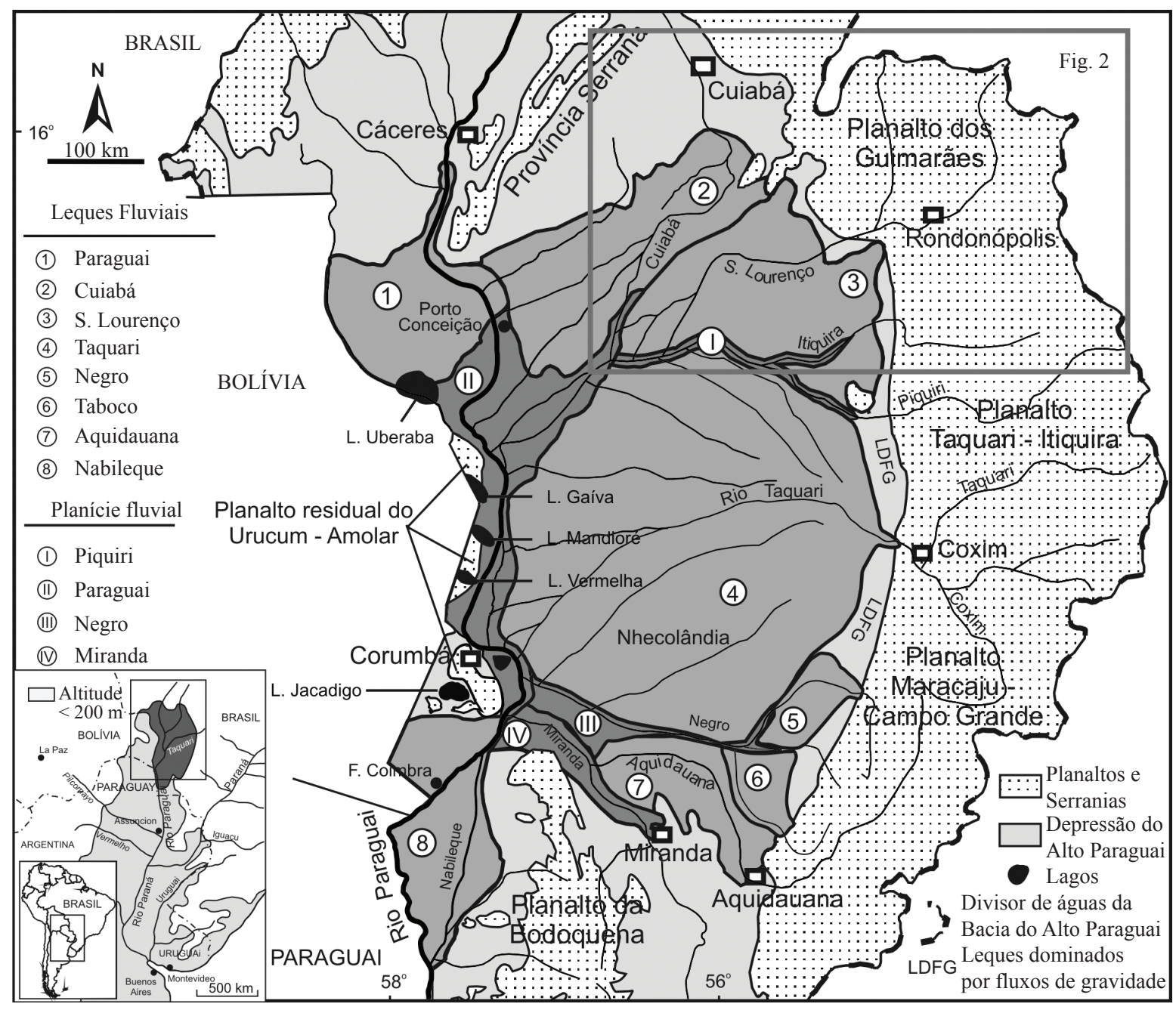

Figura 1 - Trato deposicional do Pantanal, no qual se destacam sistemas de megaleques fluviais (modificado de Assine 2003). A área estudada está indicada por retângulo (Fig. 2). 
Lourenço. Poucos quilômetros a jusante de sua confluência do rio Vermelho, o rio São Lourenço atinge a planície do Pantanal correndo num vale encaixado de direção N65E, condicionado pela falha de São Lourenço, uma estrutura antiga reativada no Quaternário.

O rio São Lourenço apresenta padrão distributário no Pantanal, aonde vem construindo um megaleque fluvial desde o Pleistoceno. Com base na compartimentação geomorfológica realizada, elementos morfológicos dos diferentes compartimentos do megaleque foram identificados e caracterizados, bem como definidos os padrões de canal, interpretados os processos da dinâmica sedimentar do sistema, reconhecidos fenômenos de avulsão fluvial e delineados lobos deposicionais.

\section{MATERIAL E MÉTODOS A compartimenta-} ção geomorfológica foi baseada na interpretação de imagens de satélite e de modelos digitais de elevação (MDE), tendo sido discriminadas zonas homólogas, padrões de drenagem e áreas inundáveis, e identificados elementos morfológicos distintos, tais como formas deposicionais, atuais e relictas, feições erosivas, terraços, fraturas e lineamentos geológicos.
Para a realização deste trabalho, foram analisadas e interpretadas imagens correspondentes às cenas 241/71, 242/71, 241/72, 242/72, 243/72 dos satélites Landsat 2 e 3 (sensor MSS, resolução de $80 \mathrm{~m}$ ), Landsat 5 (sensor TM, resolução $30 \mathrm{~m}$ ) e Landsat 7 (sensor ETM+, resolução de $30 \mathrm{~m}$ ). Em cada cena aplicaram-se processamentos básicos de registro, correções geométricas e montagem de mosaicos de bandas específicas e de composição falsa-cor. Também foram utilizadas as cenas S-21-15 e S-22-15 do mosaico de imagens (com resolução de 14,25 m) GeoCover Landsat 4/5 Circa 1990 e GeoCover Landsat 7Circa 2000.

Dados altimétricos obtidos da missão Shuttle Radar Topography Mission (SRTM), com grid de três arcos de segundo, foram usados para a confecção de MDE. Os dados foram corrigidos (eliminação de bad values) e agrupados para a confecção dos modelos. Como há pouca variação altimétrica no megaleque, foram confeccionados MDE com ajuste de cores para representar variações de $2 \mathrm{~m}$ na altimetria e realçar elementos morfológicos.

Perfis topográficos foram elaborados com base nos dados SRTM em formato ASCII (tabela x,y,z). Com o objetivo de delimitar planície atual e terraços,

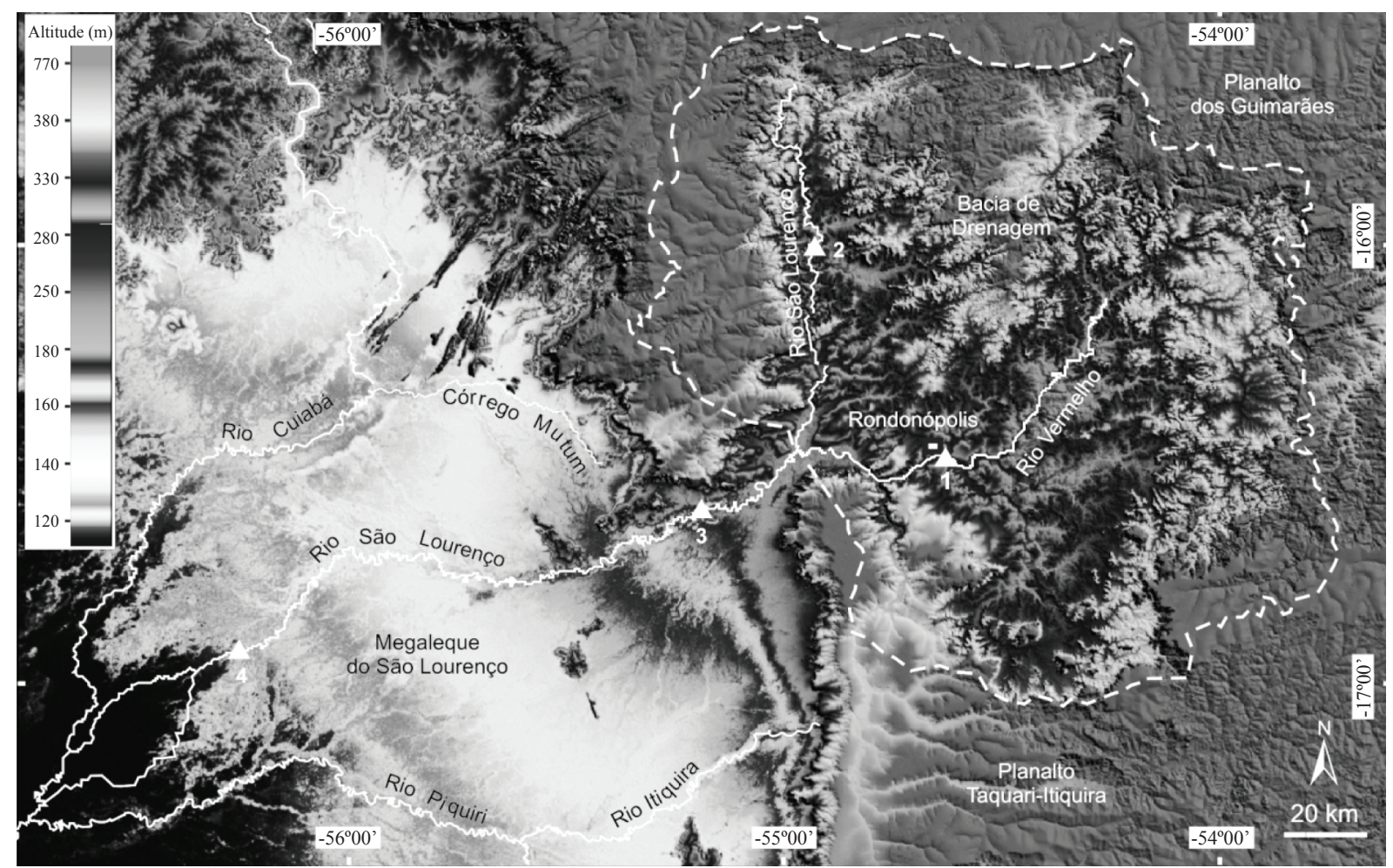

Figura 2 - Modelo digital de elevação da área estudada, com delimitação da bacia de drenagem e do megaleque do rio São Lourenço. Estações fluviométricas indicadas por triângulos: 1) Rondonópolis; 2) São Pedro da Cipa; 3) Acima do Córrego Grande; 4) São José do Borireu. Destaca-se o fato de que a área da bacia de drenagem (delimitada por linha tracejada) é semelhante à área do megaleque, que é limitado a leste pelas escarpas dos planaltos, a oeste e norte pelos rios Cuiabá e Mutum, e a sul pelos rios Piquiri e Itiquira. 
minimizando o efeito dossel da vegetação arbórea, foi empregado filtro linear de média móvel com ponderação do decaimento linear dos pesos das células com o aumento da distância em relação ao centro do filtro. Este recurso em gráfico suaviza as flutuações nos dados, permitindo definir com mais exatidão o contorno e a tendência da superfície. Este procedimento foi utilizado por Almeida et al. (2007) e Mendes et al. (2006), que obtiveram bons resultados com a redução de ruídos speckle e da influência da vegetação em dados SRTM.

As imagens processadas e os MDE foram inseridos em banco de dados com interface de manipulação de informações geográficas de diferentes fontes - Serviço Geológico do Brasil (CPRM), Agência Nacional de Águas (ANA) e Ministério do Meio Ambiente de Mato Grosso (MMA), conforme proposta de Litton (1987). Os dados, referenciados ao datum WGS-84, foram analisados e interpretados com o auxílio de ferramentas disponíveis em sistemas de informações geográficas (SIG). Os limites do megaleque do rio São Lourenço foram assim delimitados, gerando novo plano de informação, com ênfase no reconhecimento de paleocanais distributários e de canais tributários da drenagem atual.

Para dirimir dúvidas e/ou refinar a interpretação das geoformas identificadas, fez-se uso de fotografias aéreas verticais do Projeto USAF (19641967) na escala 1:60.000. Três campanhas de campo foram realizadas para verificação e validação das interpretações feitas, obtenção de dados de campo, amostragem e documentação fotográfica das formas deposicionais e erosivas reconhecidas nas imagens.

\section{RESULTADOS Ocupando área de cerca de} $16.000 \mathrm{~km}^{2}$, o megaleque do rio São Lourenço é um sistema deposicional alongado, com extensão aproximada de $200 \mathrm{~km}$ e largura de $120 \mathrm{~km}$. Seu limite oriental é definido pelo contato com pequenos leques aluviais dominados por fluxos de gravidade, ativos e inativos, formados no sopé das escarpas dos planaltos dos Guimarães e do Taquari-Itiquira, onde se situa a bacia de drenagem do megaleque. O limite sul é definido pelo megaleque do Taquari, interpondo-se entre ambos a planície fluvial dos rios Piquiri e Itiquira. Sua franja está situada na porção oeste do megaleque, sendo seus contornos delineados pela planície fluvial periférica do rio Cuiabá (Fig. 3). O ápice está situado na saída do vale através do qual o rio São Lourenço deixa o planalto e adentra na planície do Pantanal.
As altitudes têm suave caimento para oeste, de aproximadamente $200 \mathrm{~m}$ no ápice a $110 \mathrm{~m}$ na base do megaleque, situado na foz com o rio Cuiabá, resultando em gradiente baixo de cerca de $40 \mathrm{~cm} / \mathrm{km}$. As curvas de contorno, extraídas do MDE da Fig. 3, mostram morfologia característica de leques aluviais, caracterizado por padrão concêntrico centrado no ápice do sistema deposicional. A disposição dos contornos altimétricos no modelo também revelou a existência de um pequeno leque coalescente formado pelo rio Itiquira na planície do Pantanal. A geometria convexa para cima da superfície do leque é evidente em perfis topográficos transversais (Fig. 4).

A análise de imagens de satélite, de modelos digitais de elevação e de informações obtidas no campo permitiu a identificação, o mapeamento e a caracterização de três compartimentos geomorfológicos distintos: 1) lobos deposicionais abandonados, constituídos por depósitos aluviais pleistocênicos, em processo de dissecação e pedogênese; 2) cinturão de meandros, de idade holocênica, formado em vale inciso; e 3) lobos deposicionais ativos, constituídos por depósitos holocênicos sobrepondo formas relictas de idade pleistocênica (Fig. 5).

\section{Lobos deposicionais abandonados Com cerca} de $9.400 \mathrm{~km}^{2}$, os lobos abandonados abrangem por mais da metade da área do megaleque. Os lobos são constituídos por depósitos pleistocênicos de origem fluvial (Corradini 2011), cujas características e história deposicional ainda são muito pouco conhecidas e compreendidas. A superfície dos lobos apresenta paleocanais distributários, curvas de contorno concêntricas e perfil transversal convexo (Fig. 4). As altitudes decrescem de $190 \mathrm{~m}$ no ápice do leque para $120 \mathrm{~m}$ em suas porções distais, na confluência do rio Piquiri com o córrego Pindaival, do que resulta gradiente topográfico de cerca de $70 \mathrm{~cm} / \mathrm{km}$ (Fig. 5).

Paleocanais caracterizam a superfície dos lobos abandonados, como formas relictas que testemunham hidrologia constituída por redes de drenagem de padrão distributário. Os paleocanais destacam-se na superfície por serem altimetricamente mais altos que seu entorno, o que é facilmente visualizado em MDE (Fig. 3), constituindo característica típica deste tipo de sistema deposicional, como ocorre também no megaleque do Taquari (Assine 2005).

Os paleocanais distributários apresentam padrão semirradial, centrado no ápice do megaleque, que está situado no ponto em que o rio deixa o planalto 

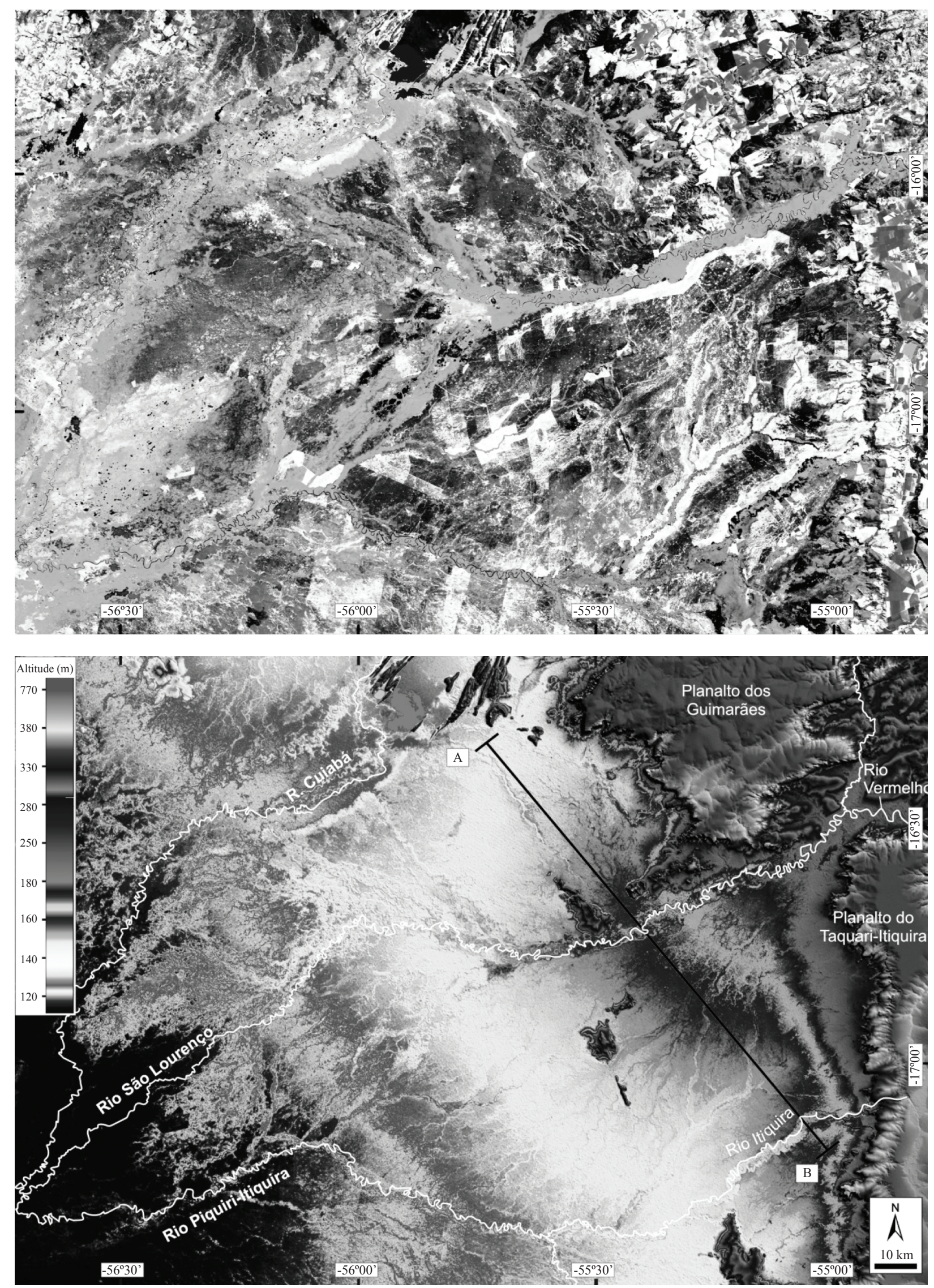

Figura 3 - A superfície do megaleque do rio São Lourenço é caracterizada pela presença de redes de canais e de paleocanais distributários, visiveis tanto em imagem de satélite (Geocover Landsat 7 Circas 2000, 7R4G2B, na parte superior da figura), quanto em modelo digital de elevação (MDE/SRTM, parte inferior da figura). O padrão concêntrico das tonalidades em escala de cinza reflete geometria convexa para cima da superficie do megaleque (AB: localização do perfil da Fig. 4). 


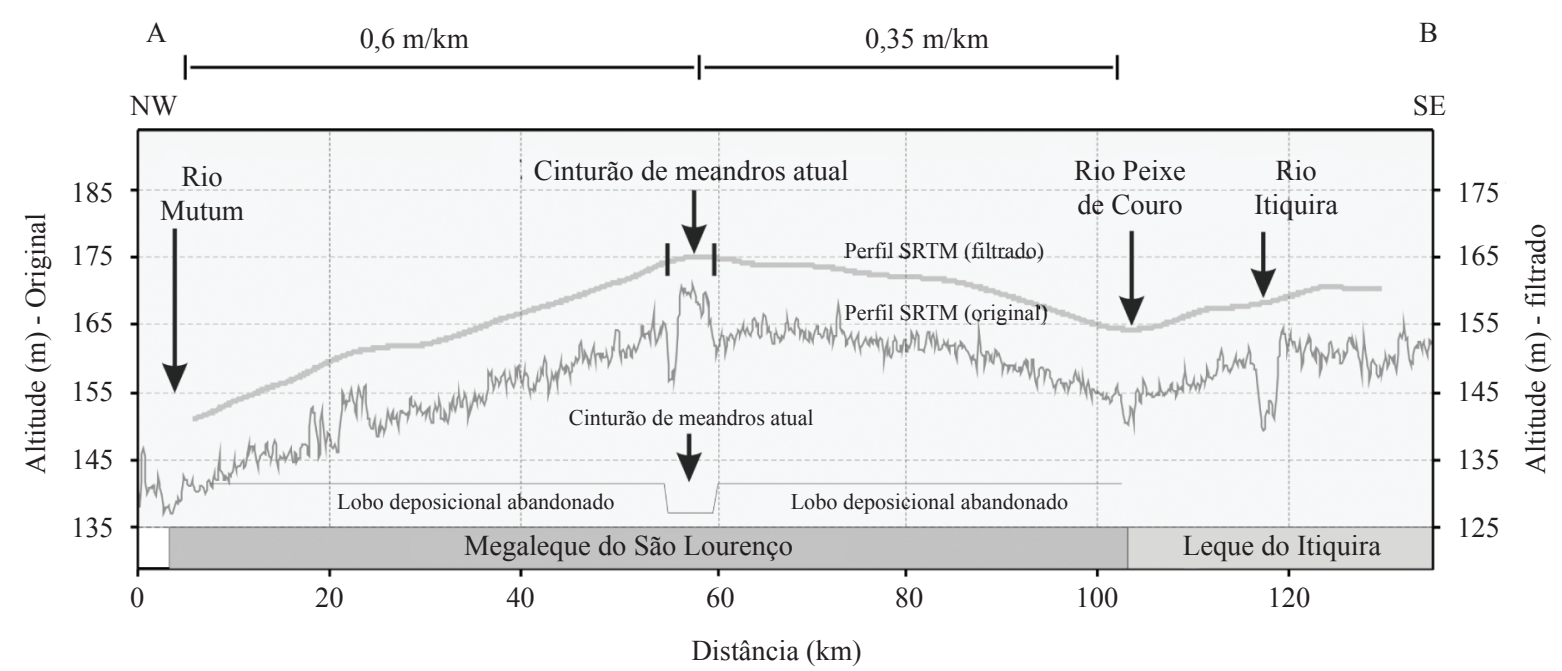

Figura 4 - Perfil topográfico na porção proximal do megaleque do rio São Lourenço, com exagero vertical de cerca de 700X, revelou geometria convexa em corte transversal. Perfil obtido com dados Shuttle Radar Topography Mission filtrados por filtros passa-baixas de 101 células (localização do perfil AB na Fig. 3).

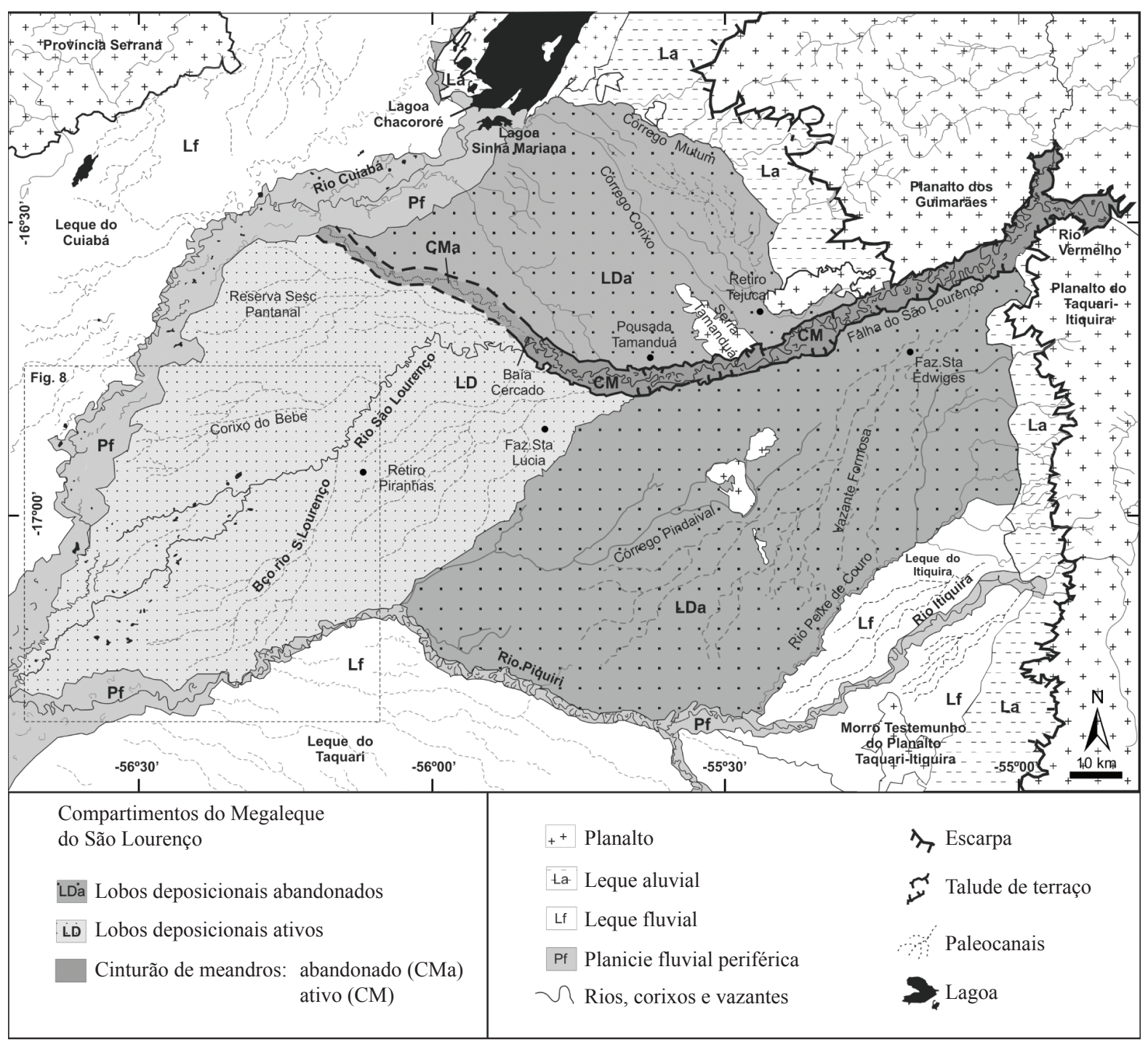

Figura 5 - Compartimentação geomorfológica do megaleque do rio São Lourenço. 
e adentra na planície do Pantanal. Destaca-se a existência de relevos residuais na planície, testemunhos da maior extensão outrora ocupada pelo planalto. Tais relevos representam obstáculos naturais, que causaram deflexões no fluxo quando os lobos eram os sítios principais de sedimentação fluvial no sistema.

Os lobos abandonados são cortados por um vale inciso na porção superior/média do megaleque, no qual se encontra embutido o cinturão de meandros do São Lourenço. A presença deste vale é a principal evidência de que os lobos vêm sendo submetidos a fenômenos de degradação, dominantemente por processos erosivos hídricos. Sedimentação ocorre apenas durante eventos de inundação, resultando numa cobertura descontínua de depósitos de pequena espessura.

Além da existência do vale inciso, que subdivide a planície em setores norte e sul, canais atuais cortam a planície, ora se ajustando ao traçado dos paleocanais, ora cortando-os, para integrar redes ativas de drenagem tributária que drenam as águas pluviais para fora do sistema deposicional em direção às planícies periféricas dos rios Itiquira (sul) e Cuiabá (norte). Tais redes encontram-se, portanto, superimpostas à paisagem da planície aluvial, dissecando o relevo e mascarando a paleodrenagem característica do megaleque.

Os canais tributários têm baixa descarga fluvial uma vez que não recebem águas da bacia de drenagem. Não há também, a não ser em casos muito excepcionais, fluxo a partir do rio São Lourenço. Os canais tributários são retilíneos, pouco profundos ( 2 a $3 \mathrm{~m}$ ) e estreitos $(5-15 \mathrm{~m})$. No setor norte os canais estão estruturalmente orientados segundo a direção $\mathrm{N} 40 \mathrm{~W}$, praticamente transversal ao curso do rio São Lourenço. Entre eles, está o córrego Corixo que flui da Serra do Tamanduá (morro testemunho) para o rio Cuiabá.

No setor sul os canais tributários são fortemente condicionados pela direção N65E, a mesma que condiciona o vale inciso do rio São Lourenço, e secundariamente pela direção N45E (Figs. 3 e 5). Esses canais são evidentes nos MDE (Fig. 3) e funcionam como coletores de água (vazantes), destacando-se, entre eles, o rio Peixe de Couro e o córrego Pindaival que drenam a área a sul do rio São Lourenço.

As planícies atuais dos rios Itiquira, Cuiabá e São Lourenço, que limitam os lobos abandonados, são ambientes dominados por processos agradacionais. Destaca-se que o limite sul da planície dissecada é definido pelo rio Itiquira e seu afluente, o rio
Peixe de Couro, que também apresenta planície em processo de agradação. O rio Itiquira, a montante da confluência com o rio Piquiri, encontra-se também em um vale inciso sobre depósitos aluviais mais antigos dele mesmo, o que permitiu o reconhecimento e delimitação do leque do Itiquira (Figs. 3 e 4).

Cinturão de meandros $\mathrm{O}$ cinturão de meandros está embutido num vale inciso encaixado na parte superior/média do megaleque. $\mathrm{O}$ vale tem orientação N65E, direção condicionada estruturalmente pela falha de São Lourenço (Fig. 5), uma estrutura antiga reativada no Quaternário. Com extensão de $80 \mathrm{~km}$ e área de aproximadamente $580 \mathrm{~km}^{2}$, o cinturão é resultado de preenchimento sedimentar por agradação fluvial, sendo seus depósitos de idade holocênica (Corradini 2011).

O cinturão de meandros apresenta variação na sua largura. Atinge sua maior expressão nas proximidades do Retiro Tejucal e na fazenda Santa Edwiges, onde tem cerca de $8 \mathrm{~km}$. Sua largura se reduz para menos de $3 \mathrm{~km}$ no trecho em que passa ao lado do morro testemunho conhecido como Serra do Tamanduá.

O rio São Lourenço é um típico rio meandrante, com barras em pontal e sinuosidade média de 2,15 (Fig. 6). Na sua planície de inundação é comum a presença de meandros abandonados, muitos formando lagos em ferradura (oxbow lakes) e espiras de meandros (scroll bars). Os meandros abandonados testemunham mobilidade lateral do rio, que tem canais extremamente sinuosos, ora com segmentos retilíneos devido à corte de colo de meandros. A migração e o abandono do canal, por translação e expansão, produzem meandros abandonados.

A altura dos terraços, que ultrapassa $5 \mathrm{~m}$ no ápice do leque, decresce de montante para jusante. Na extremidade oeste, onde as altitudes do cinturão de meandros atual e dos lobos deposicionais abandonados se tornam similares, começa a ocorrer perda significativa d'água do canal para as planícies adjacentes. Este ponto, situado nas proximidades da fazenda Santa Lúcia e pousada Tamanduá, foi considerado o ponto de interseção do megaleque. O efeito dossel da vegetação densa de porte arbóreo $(10-20 \mathrm{~m})$, existente na planície de meandros, cria artifício de superelevação do relevo nos MDE, com falsa aparência de que o cinturão de meandros está em um patamar topográfico mais elevado que o dos terraços (Figs. 4 e 6).

Mesmo com o desaparecimento dos terraços marginais, o cinturão de meandros mantem-se ativo 

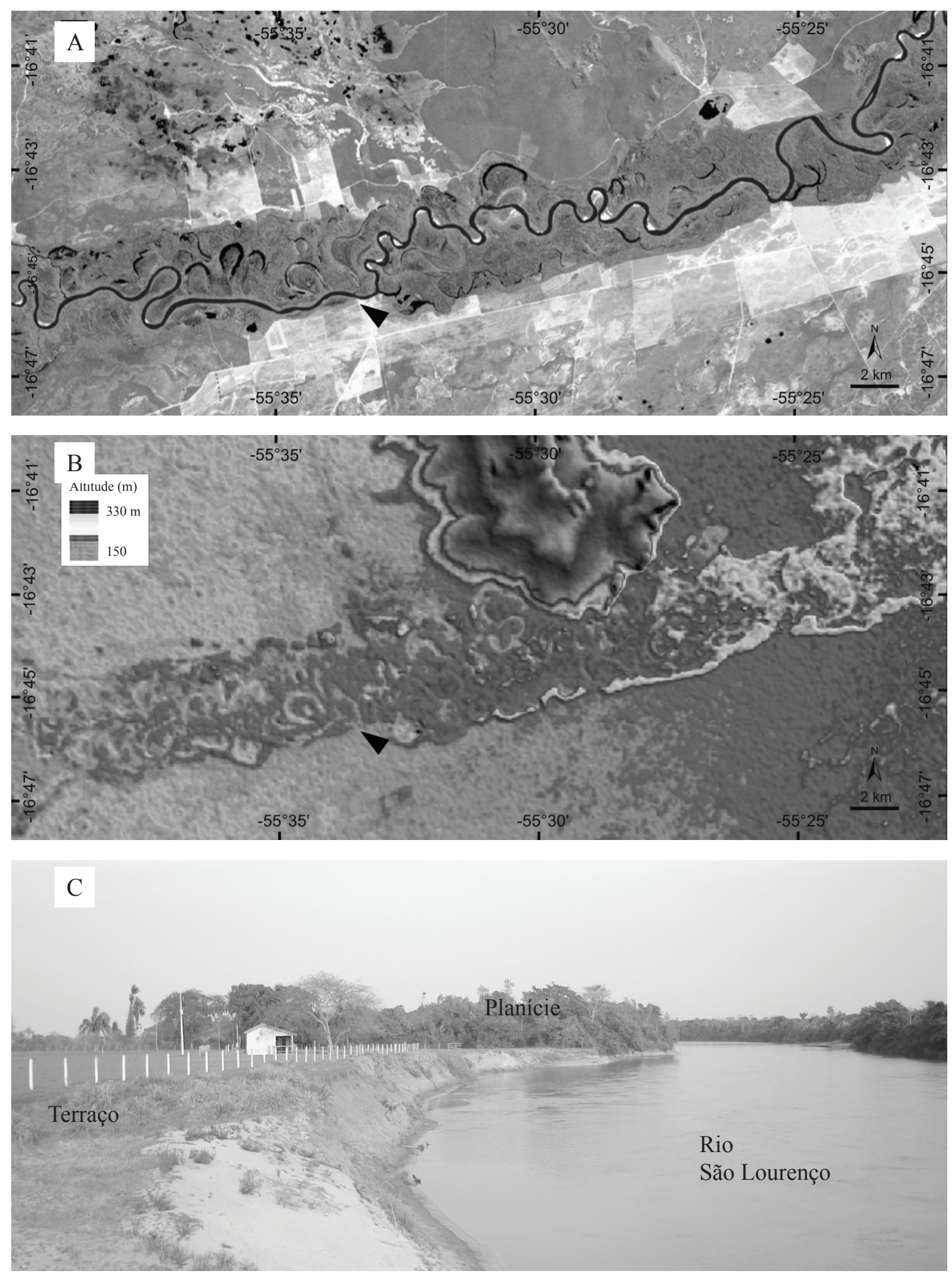

Figura 6 - Cinturão de meandros em vale inciso: (A) Depósitos holocênicos estão confinados entre sedimentos antigos dos terraços pleistocênicos marginais (imagem Landsat 7, ETM+/4R5G3B/2001); (B) Modelo digital de elevação destaca a vegetação arbórea no cinturão de meandros atual e mascara o vale inciso, o que resulta numa inversão aparente do relevo; (C) A presença de vegetação arbórea na planície de meandros é causa da inversão do relevo nos modelos digitais de elevação gerados com dados Shuttle Radar Topography Mission (a seta em A e B indica a localização da foto $C$ ). 
por mais $25 \mathrm{~km}$. Nesse trecho, a largura da planície tem em média $4 \mathrm{~km}$ e a sinuosidade do rio é de 1,9. Caracteriza-se por poucas evidências de corte de colo do meandro e pela existência de poucos lagos em ferraduras (oxybow lakes) (Fig. 6). Pontos de rompimentos de diques marginais existem em ambas as margens, porém com maior frequência na margem esquerda. Na altura da Baia do Cercado, o rio São Lourenço deflete para oeste e deixa o cinturão de meandros, adentrando no compartimento dos lobos deposicionais ativos.

Fato muito interessante foi a constatação de que o cinturão de meandros tem continuidade para jusante num trecho de cerca $50 \mathrm{~km}$ de extensão, com direção aproximada N60W, da Baia do Cercado até as proximidades da planície fluvial do Cuiabá (Fig. 5). O rio São Lourenço não mais corre neste trecho, que foi discriminado como cinturão de meandros abandonado (CMa). Seus limites são facilmente definidos em imagens de sensores remotos, bem como feições internas como paleocanais e espiras de meandro.

\section{Lobos deposicionais ativos Situado na porção} distal do megaleque do São Lourenço, este compartimento é limitado a oeste pela planície do rio Cuiabá, a sul pela planície do rio Piquiri e a norte pelo $\mathrm{CMa}$ do rio São Lourenço (Fig. 5). Com área aproximada de $5.300 \mathrm{~km}^{2}$, o lobo apresenta forma triangular, perfil longitudinal convexo, altitudes entre 114 e $154 \mathrm{~m}$, que resulta em gradiente topográfico muito baixo de cerca de $38 \mathrm{~cm} / \mathrm{km}$ (Fig. 3).

O ápice do lobo está localizado no final da porção ativa do cinturão de meandros, onde o rio São Lourenço percorre cerca de $25 \mathrm{~km}$, sem presença de terraços marginais. Neste trecho, o rio adquire a configuração de complexo de canal-dique (channel-levee complex) e se destaca altimetricamente em relação a depósitos mais antigos do cinturão. Há inúmeros pontos de rompimento de diques marginais, que recebem a denominação de "arrombados" pela população local, com formação de canais distributários na margem esquerda do rio São Lourenço.

$\mathrm{Na}$ altura da baía do Cercado (Fig. 5), o rio deflete para sudoeste e adentra no compartimento distributário, sobrepondo paisagens mais antigas remanescentes de lobos abandonados, mascarando formas deposicionais relictas, mais ou menos preservadas, formadas em condições ambientais e numa configuração geográfica diferentes da atual. Este fenômeno é observado em todo o lobo distributário atual, de forma que sedimentos holocênicos estão sobrepondo depósitos pleitocênicos de lobos abandonados existentes dentro da área do compartimento dos lobos deposicionais ativos.

Divisão de canais, formação de distributários e avulsão fluvial caracterizam a dinâmica hidrológica e sedimentar da área, que é caracterizada pela presença de vários lobos deposicionais. Como resultado, a descarga fluvial sofre significativa e contínua redução, do ápice do lobo até a confluência do rio São Lourenço com o rio Cuiabá (Fig. 7). Paralelamente, o índice de sinuosidade do canal do São Lourenço diminui para jusante, passando o estilo de meandrante na parte superior para anastomosado na parte inferior.

O lobo deposicional atual está sendo construído na extremidade sudoeste do megaleque, próximo à confluência dos rios São Lourenço e Cuiabá (Fig. 5). O formato lobado, alongado no rumo SW, é facilmente visualizado, tanto em imagens de satélite quanto em MDE. Seu contorno é definido pelos canais intermitentes do corixo do Bebê e do braço do rio São Lourenço (Fig. 8). Trata-se de área de sedimentação ativa, na qual frequentes mudanças de curso do

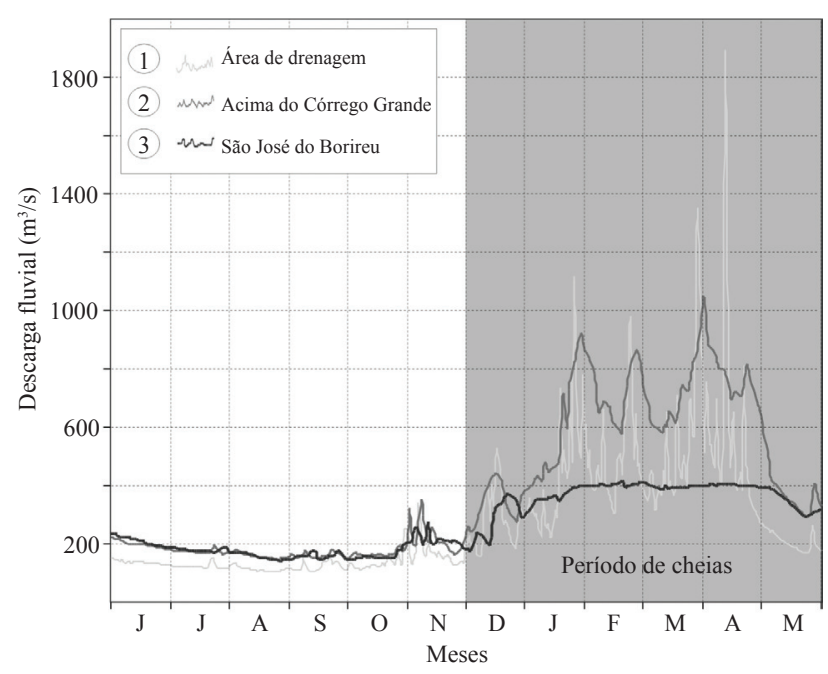

Figura 7 -Descarga fluvial do rio São Lourenço entre os meses de junho de 2002 e maio de 2003. A estação São José do Borireu, situada no compartimento dos lobos deposicionais ativos, registra pequeno aumento da descarga fluvial em relação à estação situada na bacia de drenagem durante o periodo de estiagem. Por outro lado, durante o periodo de cheias, a descarga fluvial é significativamente menor na estação São José do Borireu devido à perda de água do canal para a planície de inundação. O termo de referencia área de drenagem equivale a soma nas vazões das estações Rondonópolis e São Pedro da Cipa (localização das estações fluviométrica na Fig. 2). 
canal principal promovem alterações nos sítios de deposição, numa dinâmica de avulsão fluvial, construção e abandono de lóbulos deposicionais (Corradini et al. 2009). Exemplo disto é o canal conhecido como corixo do Bebê, localizado na margem direita do São Lourenço, que formou um lóbulo anterior ao atual. O corixo do Bebê, que já foi o canal principal do São Lourenço, funciona apenas como canal de drenagem das águas durante as cheias.

DISCUSSÃO Paleocanais existentes no ápice do leque evidenciam que o padrão de drenagem distributário se estabeleceu inicialmente em posição muito proximal, o que contribuiu para a sedimentação dos depósitos aluviais mais antigos, agora pertencentes aos lobos deposicionais abandonados. A redução da velocidade de fluxo, derivada do desconfinamento e do fluxo em lençol durante as cheias, promoveu grande mobilidade dos canais distributários e a consequente deposição da carga transportada. Mudanças frequentes de curso, controladas por baixos topográficos laterais e interlobos, promoveram a construção de complexos de canal-diques (channel-levees), o que contribuiu para a formação de lobos deposicionais pleistocênicos alongados no sentido jusante.

Importantes alterações nas condições climáticas ocorreram no Pantanal do final Pleistoceno ao Holoceno médio (Assine \& Soares 2004, Bezerra \& Mozeto 2008). Mudança nos perfis de equilíbrio do rio São Lourenço e dos rios periféricos promoveram incisão fluvial e degradação da paisagem do megaleque como um todo. Considerando a existência do cinturão de meandros formado pelo rio São Lourenço no Holoceno, alojado num vale inciso em depósitos pleistocênicos, que se estende da antiga foz no rio Cuiabá à parte superior do leque (Figs. 3 e 5), conclui-se que a incisão ocorreu em intervalo do final do Pleistoceno ao início do Holoceno.

Incisões devido à queda do nível base são comuns em megaleques fluviais, seja por mudanças climáticas e/ou por eventos tectônicos. Shukla et al. (2001) e Fontana, Mozzi \& Bondesan (2008) interpretaram mudanças climáticas no Pleistoceno como causa para incisões verificadas, respectivamente, nos megaleques do Ganges (Índia) e de Brenta e Tagliamento (Itália). Por outro lado, Maher \& Harvey (2008) consideraram que incisão existente no rio Alias (Espanha) teve como causa movimentos tectônicos associados a zonas de falha.

Assine (2010) interpretou que significativo aumento da precipitação, do final do Pleistoceno ao início do Holoceno, promoveu aumento da descarga fluvial e redução do aporte sedimentar em conseqüência da revegetação das bacias de drenagem, o que teria sido a causa da incisão nas porções proximais dos megaleques fluviais existentes no Pantanal, como é o caso do Taquari (Assine 2005) e do Paraguai (Assine \& Silva 2009).

Utilizando a mesma linha de raciocínio, interpreta-se que a incisão constatada na porção proximal do megaleque do São Lourenço foi consequência da conjugação do aumento da descarga fluvial com a redução do aporte sedimentar no início do Holoceno. Posteriormente, à medida que houve diminuição da descarga fluvial, devido à interveniência de climas menos úmidos durante o Holoceno, o perfil de equilíbrio do rio São Lourenço se elevou dando origem ao cinturão de meandros por agradação fluvial. Os mesmos eventos de incisão e agradação fluvial são observados nos vales dos rios Itiquira e Piquiri, assim como nos canais de pequeno porte situados nos lobos abandonados (Fig. 3).

Estes eventos de modificação do perfil de equilíbrio fluvial, com formação de vale inciso e sua posterior agradação por depósitos de rio meandrante, causaram importante transformação na paisagem do megaleque. $\mathrm{O}$ ápice dos lobos, antes situado na porção superior do sistema, foi deslocado para a porção média/inferior, estando hoje situado nas proximidades da fazenda Santa Lúcia e da pousada Tamanduá, no trecho final do cinturão de meandros ativo, onde foi interpretado o ponto de intersecção do sistema (Fig. 5). De fato, o rio passa a ter características de canal-diques entre a fazenda Santa Lúcia e a baia do Cercado, com inúmeros pontos de rompimento e paleocanais distributários na margem esquerda do rio.

Com o objetivo de melhor caracterizar a localização do ponto de intersecção, interpretada com base em dados orbitais, foram construídos dois perfis topográficos com dados de MDE: a) um sobre a superfície dos lobos abandonados no terraço a sul do rio São Lourenço; e b) outro na superfície deposicional constituída pelo cinturão de meandros e lobos deposicionais ativos (Fig. 9). Os perfis não permitiram definir com precisão a localização do ponto de intersecção, pois os dados SRTM apresentam ruídos de efeito speckle e erro de precisão altimétrica inerentes ao próprio modelo e à influência das coberturas de vegetação. A despeito disto, ficou evidente nos perfis que ocorre inversão da superfície deposicional atual em relação à superfície dos lobos antigos, em local aproximadamente coincidente com a transição do 

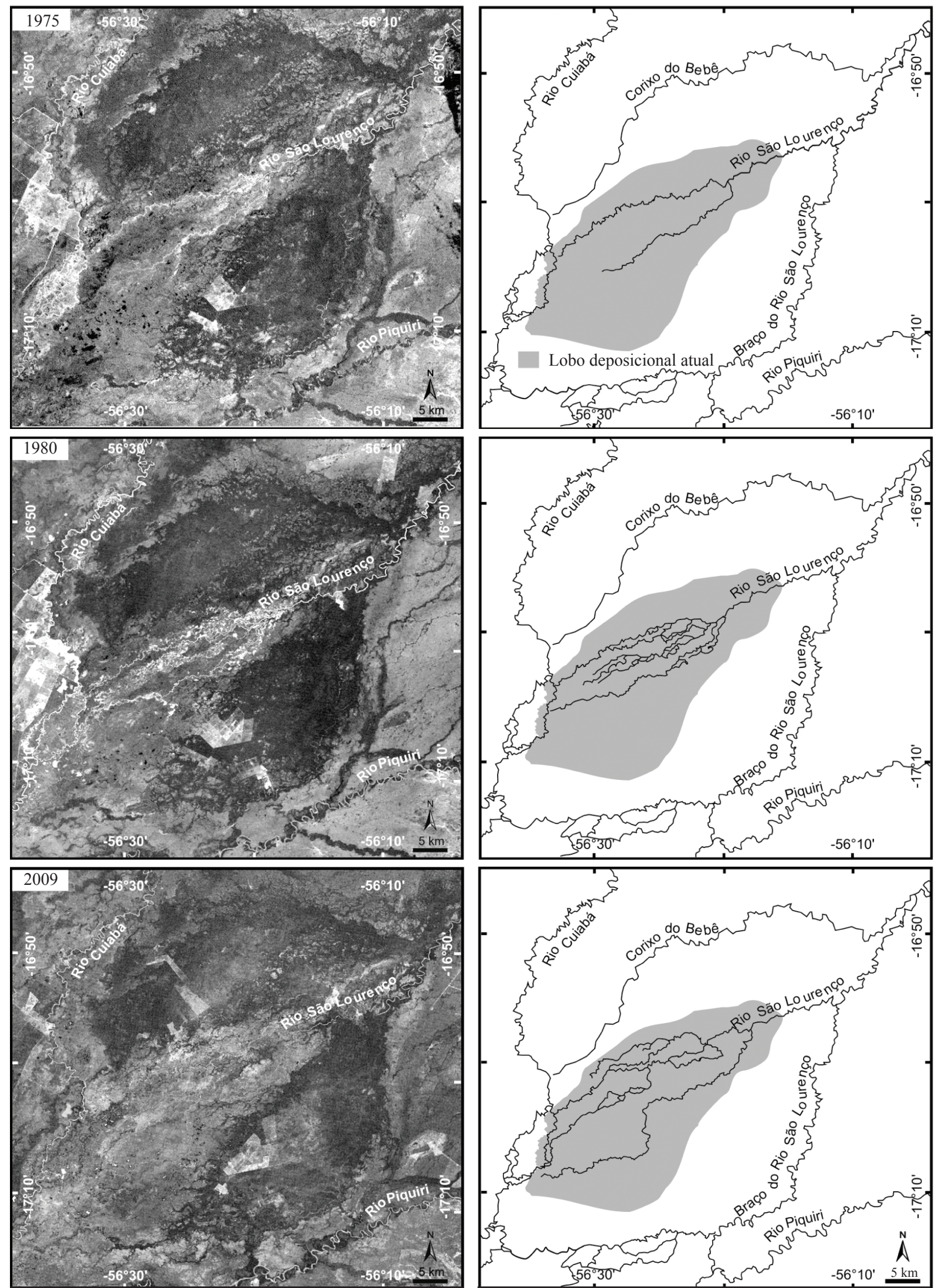

Figura 8 - Mudanças morfológicas no lobo deposicional atual: (A) havia um canal bem definido no ano de 1975, com apenas um distributário situado na sua margem direita (imagem Landsat 2/MSS/Banda 4); (B) Diversos canais distributários são visiveis na imagem de 1980 (imagem Landsat 3/MSS/Banda 4); (C) Devido à alta taxa de suprimento sedimentar, canais anastomosados se estabelecem dando origem a um novo lóbulo deposicional (imagem Landsat 7/ETM+/Banda 4). 
cinturão de meandros para o ápice dos lobos modernos. A montante do ponto de intersecção, a superfície do terraço se torna cada vez mais alta em relação ao cinturão de meandros, enquanto que complexos de canal-diques e lóbulos deposicionais caracterizam o compartimento dos lobos ativos.

Os lobos situados na porção distal do megaleque são o principal sítio de deposição de sedimentos. Devido ao fato de que os complexos de canal-diques progressivamente crescem na vertical, empilhando fácies de areias de formato linear, há tendência natural à ocorrência de rompimento dos diques marginais e fluxo para as planícies adjacentes, situadas em patamar topográfico mais baixo. Quando há abandono do canal e mudança definitiva para um novo curso, ocorre o fenômeno de avulsão (Aslan, Autin, Blum 2005). Desta forma, o fenômeno se repete com o desenvolvimento de um novo complexo de canal-diques, que
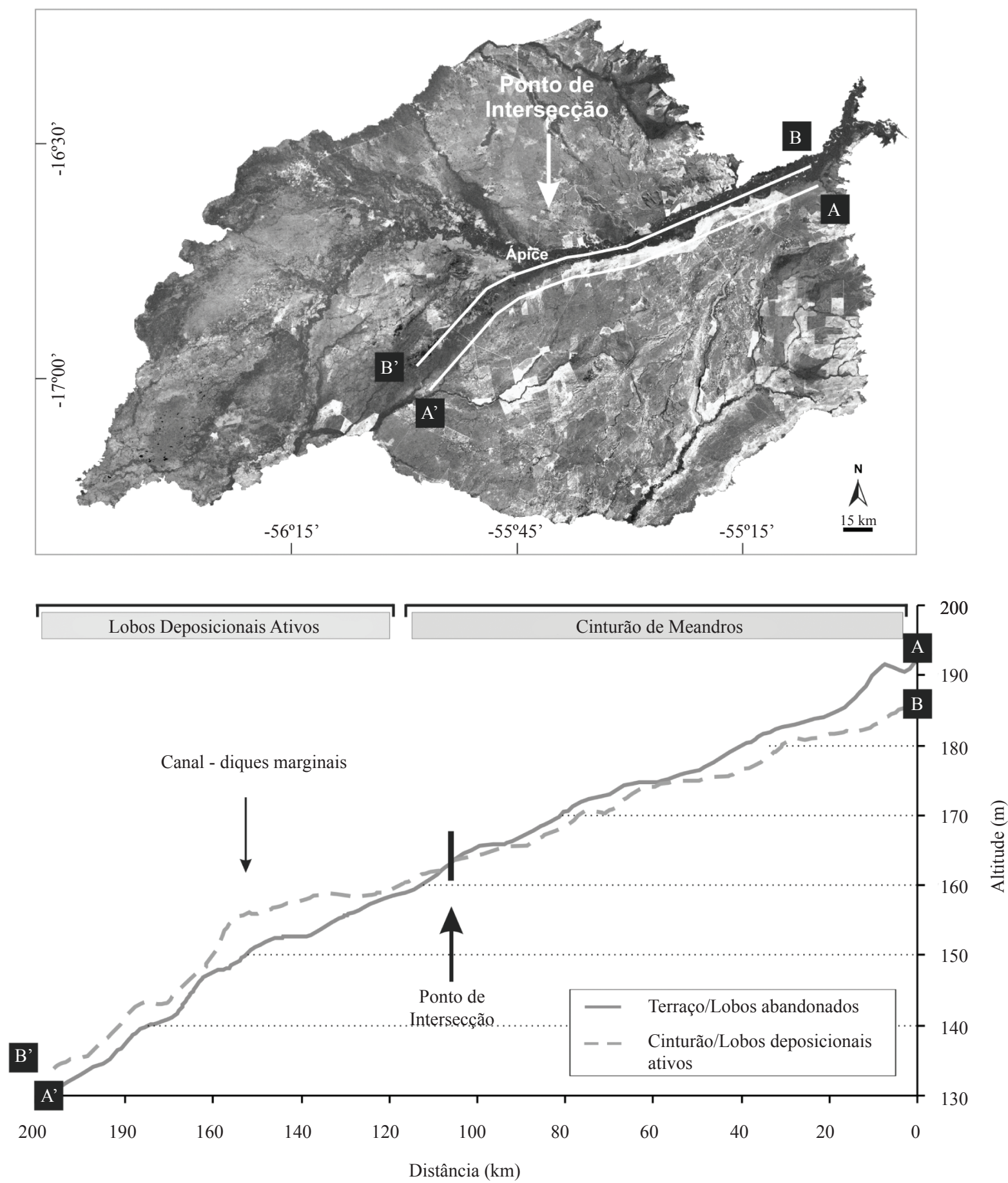

Figura 9 - Ponto de intersecção do megaleque, definido a partir de perfis gerados com dados de Shuttle Radar Topography Mission (aplicados em filtros passa-baixas de 101 células). Os dados da linha A-A'foram extraídos do terraço e os da linha B-B' da superfície deposicional atual (localização dos perfis está indicada em imagem Geocover Circas 2000, 2B7R4G). 
pode terminar num lóbulo por desconfinamento e espraiamento (terminal splay). Esta evolução típica de sistemas distributários desempenha importante papel na construção deste tipo de sistema deposicional. Fenômenos de avulsão caracterizam outras áreas do Pantanal (Ab'Saber 1988), como por exemplo nos megaleques do Taquari (Assine 2005, Assine et al. 2005), do Paraguai (Silva et al. 2007, Assine \& Silva 2009) e do Nabileque (Kuerten et al. 2009, Kuerten \& Assine 2011).

Nos lobos deposicionais ativos do megaleque do São Lourenço, canais abandonados, com mesmas dimensões do atual canal do São Lourenço, revelam recorrência de fenômenos de avulsão e formação de lóbulos deposicionais. Revelam também que o rio São Lourenço já foi afluente do rio Piquiri, quando seu canal principal era o que é hoje conhecido como braço do rio São Lourenço (Figs. 5 e 8).

Redução da vazão do rio é fenômeno comum em sistemas distributários, seja pelas bifurcações do canal, seja pela perda d'água para a planície, tanto pelos pontos de ruptura nos diques marginais quanto por extravasamento durante as cheias. No caso do São Lourenço, verifica-se redução superior a $300 \mathrm{~m}^{3} / \mathrm{s}$ nos valores de vazão quando se comparam os dados da estação Acima do Córrego Grande (cinturão de meandros) com a de São José do Borireu (lobo deposicional atual) (Fig. 7).

Os processos relacionados a uma avulsão fluvial seguem ordem evolutiva previsível. Inicialmente há o rompimento do canal e, à medida que a água é desviada para a planície, um canal distributário se forma com a divisão do canal principal. Bifurcações do canal podem levar a um padrão distributário da drenagem e mudança do canal principal. A sedimentação nos canais distributários dá origem a corpos lineares, com ou sem lóbulos na sua extremidade. A velocidade com que esses processos sedimentares ocorrem depende de muitas variáveis (vazão, carga sedimentar, profundidade do canal, vegetação ciliar, dinâmica das cheias etc.). A velocidade com que os processos vem ocorrendo no São Lourenço é da mesma magnitude que o observado no megaleque do Taquari (Assine 2005, Assine et al. 2005), ou seja, de poucas décadas, fato documentado por imagens de satélite obtidas no período de 1975 a 2009 (Fig. 8).

CONCLUSÕES O megaleque do São Lourenço é um sistema deposicional constituído por um mosaico de feições morfológicas quaternárias que evidenciam uma sucessão de eventos de deposição e erosão. O desconfinamento do fluxo proveniente da bacia de drenagem, situada nos planaltos adjacentes, foi responsável pela formação de lobos deposicionais proximais durante o Pleistoceno.

Mudanças climáticas, ocorridas do Pleistoceno tardio ao Holoceno, foram fator de importância fundamental na reconfiguração da paisagem, sobretudo responsáveis por mudanças na descarga fluvial, por processos de incisão, de deposição por agradação fluvial no cinturão de meandros, e por progradação nos lobos deposicionais.

O cinturão de meandros, embutido num vale inciso em sedimentos pleistocênicos na parte superior do sistema, destaca-se como feição marcante na paisagem e na evolução do megaleque do São Lourenço. A formação do vale é atribuída ao aumento da vazão fluvial na passagem do Pleistoceno para o Holoceno. Com a avulsão do rio São Lourenço, que abandonou o cinturão de meandros no seu baixo curso, o ponto de intersecção se deslocou para oeste e lobos deposicionais passaram a ser construídos na porção distal do sistema.

O cinturão de meandros comporta-se agora como zona de passagem (bypass) de sedimentos da bacia de drenagem para os lobos deposicionais situados na porção distal do megaleque do São Lourenço. Situado próximo à confluência com o rio Cuiabá, o lobo deposicional atual é hoje o mais importante sítio deposicional, caracterizado por mudanças rápidas na sua paisagem geográfica.

A compreensão da dinâmica sedimentar e a quantificação dos processos de transferência de matéria ao longo do sistema é passo fundamental para a previsão de futuras tendências de mudança na paisagem do megaleque do São Lourenço, importante subsídio para definição de políticas públicas de preservação e de desenvolvimento sustentável da região.

AGRADECIMENTOS Os autores agradecem à Fundação de Amparo à Pesquisa do Estado de São Paulo (FAPESP) pelo apoio à pesquisa (Processo $n^{\circ}$ 2007/55987-3). Ao Conselho Nacional de Desenvolvimento Científico e Tecnológico (CNPq) pelo apoio à pesquisa (Processo $n^{\circ} 484300 / 2011-3$ ), pela concessão de bolsa PQ a Mario Luis Assine (Processo $n^{\circ}$ 305108/2009-3); ao CNPq e à Coordenação de Aperfeiçoamento de Pessoal de Nível Superior(CAPES) pela concessão de bolsa de doutorado para Fabrício Aníbal Corradini no Programa de Pós-graduação em 
Geociências e Meio Ambiente da UNESP, Campus de Rio Claro. À Secretaria de Estado do Meio Ambiente (SEMA)/MT, Regional de Rondonópolis, pelo apoio logístico durante os trabalhos de campo, em especial a Fernando Luiz Mews, José Custódio Dias e Salvino Ferreira Farias; a geógrafa Sinthia Cristina Batista.

\section{Referências}

Ab'Saber A.N. 1988. O Pantanal Mato-Grossense e a teoria dos refúgios. Revista Brasileira de Geografia, 50 (n. especial):9-57.

Almeida T.I.R., Fernandes E., Mendes D., Branco F.C., Sigolo J.B. 2007. Distribuição espacial de diferentes classes de lagoas no Pantanal da Nhecolândia, MS, a partir de dados vetoriais e SRTM: uma contribuição ao estudo de sua compartimentação e gênese. Revista do Instituto de Geociências - Série Cientifica USP. São Paulo, 7:95-107.

Aslan A., Autin W.J., Blum M.D. 2005. Causes of river avulsion: insights from the Late Holocene avulsion history of the Mississippi River, U.S.A. Journal of Sedimentary Research, 75:650-664.

Assine M.L. 2003. Sedimentação na Bacia do Pantanal Mato-Grossense, Centro-Oeste do Brasil. Tese de LivreDocência, Instituto de Geociências e Ciências Exatas, Universidade Estadual Paulista, Rio Claro, 106 p.

Assine M.L. 2004. A bacia sedimentar do Pantanal MatoGrossense. In: Mantesso Neto, V., Bartorelli, A., Carneiro, C.D.R., Brito Neves, B.B. (eds) Geologia do continente sul-americano: evolução da obra de Fernando Flávio Marques de Almeida. São Paulo, Beca, capítulo IV, p 61-74.

Assine M.L. 2005. River avulsions on the Taquari megafan, Pantanal wetland, Brazil. Geomorphology, 70:357-371.

Assine M.L. 2010. The Late Cenozoic Pantanal Basin West-Central Brazil In: 2010 AGU Meeting of the Americas. 2010, Foz do Iguassu. AGU, 2010, Abstracts... U42A-05.

Assine M.L. \& Silva A. 2009. Contrasting fluvial styles of the Paraguay River in the northwestern border of Pantanal wetland, Brazil. Geomorphology, 113:189-199.

Assine, M.L. \& Soares, P.C. 2004. Quaternary of the Pantanal, west-central Brazil. Quaternary International, 114:23-34.

Assine M.L., Padovani C.R., Zacharias A.A., Angulo R.J., Souza M.C. 2005. Compartimentação geomorfológica, processos de avulsão fluvial e mudanças de curso do Rio Taquari, Pantanal Mato-Grossense. Revista Brasileira de Geomorfologia, 6:97-108.

Bezerra M.A.O. \& Mozeto A.A. 2008. Deposição de carbono orgânico na planície de inundação do rio Paraguai durante o Holoceno Médio. Ecologia Brasiliensis, 12(1):155-171.

Corradini F.A. 2011. Geomorfologia fluvial, mudanças ambientais e evolução do megaleque do rio São
Lourenço, Quaternário do Pantanal Mato-Grossense. Rio Claro, UNESP/IGCE, Tese de Doutorado, 164 p.

Corradini F.A., Zani H., Assine M.L., Kuerten S., Silva A., Gradella F.S. 2009. Paleocanais distributários, incisão fluvial, construção e abandono de lobos deposicionais na evolução geomorfológica do megaleque do São Lourenço, Pantanal Mato-grossense. In: $2^{\circ}$ Simpósio de Geotecnologias no Pantanal, Corumbá - MS, INPE, p. 115-123.

Fontana A., Mozzi P., Bondesan A. 2008. Alluvial megafans in the Venetian-Friulian Plain (north-eastern Italy): Evidence of sedimentary and erosive phases during Late Pleistocene and Holocene. Quaternary International, 189:71-90.

Kuerten S., Assine M.L., Corradini F.A., Gradella F.S.S., Silva A. 2009. Rio Nabileque: antigo curso do rio Paraguai? In: Anais do $2^{\circ}$. Simpósio de Geotecnologias no Pantanal. Corumbá (MS): Embrapa Informática Agropecuária/INPE, p. 194-201.

Kuerten S., Assine M.L. 2011. O rio Paraguai no megaleque do Nabileque, sudoeste do Pantanal Mato-Grossense, MS. Revista Brasileira de Geociências, 41:655-666.

Litton G. 1987. Introduction to database management: a pratical approach. William C. Brown, 532 p.

Maher E. \& Harvey A.M. 2008. Fluvial system response to tectonically induced base-level change during the late-Quaternary: The Rio Alias southeast Spain. Geomorphology, 100:180-192.

Mendes D., Almeida T.I.R., Fernandes E., Sigolo J.B. 2006. Utilização de imagens SRTM para a confecção de perfis altimétricos em varredura na baixa Nhecolândia, Pantanal, MS: considerações sobre a atividade neotectônica. In: Anais $1^{\circ}$ Simpósio de Geotecnologias no Pantanal. Campo Grande (MS): Embrapa Informática Agropecuária/INPE, p. 200-209.

Shukla U.K., Singh I.B., Sharma M., Sharma S. 2001. A model of alluvial megafan sedimentation: Ganta Megafan. Sedimentary Geology, 144:243-262.

Silva A., Assine M.L., Zani H., Souza Filho E.E., Araújo B.C. 2007. Compartimentação Geomorfológica do Rio Paraguai na Borda Norte do Pantanal Mato-Grossense, Região de Cáceres - MT. Revista Brasileira de Cartografia, 59:73-81.

Manuscrito ID 26174

Recebido em: 21/03/2012 Aprovado em: 28/06/2012 